
\title{
28 Research Suare \\ Relations of Dietary patterns and sleep disorders in shift workers
}

Reihaneh Khorasaniha

Tehran University of Medical Sciences

Gity Sotoudeh

Tehran University of Medical Sciences

Alireza Milajerdi

Tehran University of Medical Sciences

Farahnaz Khajehnasiri ( $\sim$ khajenasiri@tums.ac.ir)

Tehran University of Medical Sciences

Primary research

Keywords: Dietary pattern, Eat, Shift workers, Sleep disorders

Posted Date: January 20th, 2021

DOl: https://doi.org/10.21203/rs.3.rs-150189/v1

License: (c) (i) This work is licensed under a Creative Commons Attribution 4.0 International License. Read Full License 


\section{Abstract}

Background \& aims

Few studies have been done on the association of dietary intakes with SDs among shift workers, in particular those exposed to air pollution. We aimed to investigate the association of major dietary patterns with risk of SDs in shift workers of a cement factory in Iran.

Methods

This cross-sectional study was carried out on 257 male shift workers in a cement factory in Iran. Usual dietary intake of participants was assessed using a validated self-administrated 147-item dish-based FFQ. To examine sleep disturbances of participants, we used the Epworth Sleepiness Scale (ESS).

Results

Three major dietary patterns including Classic Iranian (Cl), Modern Iranian (MI), and High Protein Low Fruit and vegetables (HPLF) were identified. The $\mathrm{Cl}$ pattern was mainly consisted of high-protein animal foods, fruit and vegetables, while, the MI pattern had high amounts of refined grains, solid oils, and caffeine drinks. No significant association was found between adherence to the $\mathrm{Cl}$ pattern and risk of SDs (OR: 2.33; 95\% Cl: 0.69, 7.81) and also for the MI dietary pattern (OR: 0.62; 95\% Cl: 0.20, 1.93). However, we found a significant direct association between the HPLF dietary pattern and risk of SDs (OR: $3.92 ; 95 \% \mathrm{Cl}: 1.03,14.86)$.

Conclusion

This study showed a significant direct association between a dietary pattern high in animal proteins and solid oils and low in fruit and vegetables with risk of sleep disorders among shift workers in the cement factory. However, no such association was found for the two other dietary patterns.

\section{Introduction}

Sleep Disorders (SDs) are common among shift workers (1). Shift working disturbs normal sleep in these subjects (2). Disturbances in circadian rhythm might cause metabolic disorders such as hypertension, dyslipidemia, hyperglycemia, and abdominal obesity (3). Cement factory shift workers are frequently suffered from SDs, which are intensified by air pollution in such environment (4). SDs cause various health problems in these subjects and will reduce their ability to work (5).

Unhealthy dietary intakes are among the most important risk factors of SDs $(6,7)$. High intake of fruit and vegetables has been associated to the lowered risk of SDs $(8,9)$. In contrast, a significant direct association has been found between high intake of red meat and processed foods, as well as fried foods with risk of SDs (10). In addition, some studies have shown that SDs were less common among those with frequent caffeine intake (11). However, some other studies showed significant increase in SDs 
following high intake of caffeine (12). Shift workers are susceptible to SDs because of their working programs (1). In addition, air pollution is one of the factors causing SDs in cement factory workers (4). Shift working also alters the dietary intake of workers, which might result in several mental disorders (13). Adherence to a healthy dietary pattern, characterized by high intakes of vegetables, mushrooms, potatoes, seaweeds, soy products, and eggs, once or more a week in a study among Japanese workers, was associated with a decreased prevalence of difficulty in sleep (14). In another study in Japanese workers, low intake of vegetables and fish, high intake of sweets and noodles and unhealthy eating habits were independently associated with poor sleep quality. Poor sleep quality was also associated with high carbohydrate intake in that study (15).

Few studies have been done on the association of dietary intakes with SDs among workers, in particular shift workers. In addition, this association might be influenced by the environment of the workplace. Moreover, studies on the association of dietary pattern with sleep disorders are commonly done among western populations, we all know that dietary patterns are greatly different between populations. Therefore, we aimed to investigate the association of major dietary patterns with risk of SDs in shift workers of a cement factory in Iran.

\section{Methods}

\section{Study design and participants}

This cross-sectional study was carried out on 257 male workers in one of the biggest cement factories in Iran. Participants had at least a 6-month experience and were 20-60 years old. All workers examined were shift workers with shift periods of three weeks. The first two weeks they work on alternate days from $3 \mathrm{pm}$ to $7 \mathrm{am}$, and the last week their work schedule is daily from $7 \mathrm{am}$ to $3 \mathrm{pm}$. Shift workers who had a body mass index of less than $40 \mathrm{~kg} / \mathrm{m}^{2}$, without kidney, liver, cardiovascular, and thyroid diseases or diabetes or cancer, did not take any supplements, vitamins or minerals in the past month or omega-3 supplements in the last three months, were included. Subjects who smoked or those who were on a specific dietary pattern, were not included in the current study. Full explanations about the purposes and methods of the study were given to the participants and then their written consent was obtained.

\section{Assessment of dietary intake}

Dietary intake of participants was assessed using a 147-item, semi-quantitative Food Frequency Questionnaire (FFQ). The reliability and validity of this questionnaire has been confirmed previously (16). Participants were asked to report the frequency of consumption of each food item per day, week, month, and year. These amounts were then converted to grams per day using household measurements. Finally, participants' energy, macro- and micro-nutrients intake were calculated using the Nutritionist 4 software, modified for Iranian foods.

\section{Assessment of sleep quality}


Sleep quality was estimated with Epworth Sleepiness Scale (ESS), which has 8 questions (17). The subjects were asked to rate, on a 4-point scale (0-3), their probability of falling asleep while engaged in eight different activities. The ESS score was calculated by adding the scores for the eight questions. ESS scores were divided into two groups, zero to 10 as the desirable and $11-24$ as the undesirable situation (18).

\section{Assessment of other variables}

Participants' physical activity was assessed using the International Physical Activity Questionnaire (IPAQ) (19), and converted to metabolic equivalents (MET) in terms of min/week (MET-min/week) based on references. The validity of Persian version of the questionnaire had been approved previously (20). The participants' weight was measured using Seca digital scale (755, Germany) to the nearest 100 gram with the subjects wearing light clothing without shoes. Participants' height was also measured by a stadiometer while the subject's shoulders were in normal position to the nearest $1 \mathrm{~cm}$. BMI was calculated by dividing the weight $(\mathrm{kg})$ to height squared $\left(\mathrm{m}^{2}\right)$. Eventually, participants' waist circumference was measured in the middle of last rib and iliac crest to the nearest $1 \mathrm{~cm}$.

\section{Statistical analysis}

Factor analysis was used to identify major dietary patterns. First, due to the large number of food items, we assigned each food item into 22 predefined food groups based on the similarity in their nutrient contents (Table 1). Principal component analysis was done with the factors rotated by orthogonal transformation. The natural interpretation of the factors in conjunction with eigenvalues $(\geq 1.3)$ and Scree plot determined whether a factor should be retained. Identified dietary patterns were labelled on the basis of our interpretation of data and on prior literature. The factor score for each pattern was calculated by summing intakes of food groups weighted by their factor loadings, and each participant received a factor score for each identified pattern. Participants were then categorized based on tertiles of dietary pattern scores. To determine the association of dietary patterns with sleep quality, we used multivariate logistic regression. The first tertile of dietary pattern scores was considered as the reference in each model. Regression analysis was controlled for participants' age, BMI, marital status, education, physical activity, and total energy intake in different models. All statistical analyses were done using the Statistical Package for Social Sciences software (SPSS Inc, version 16). 
Table 1

Food grouping used in the dietary pattern analysis

\section{Food Food items \\ group}

Whole Barley, corn

grains

Refined Vermicelli, spaghetti and pasta, boiled potato, cooked rice, breads, Baguettes grains

Egg Egg

Legumes Lentils, beans (white, red, pinto), chickpeas, soybeans, mung beans, split peas, peanuts, \& nuts almonds, walnuts, pistachios, nuts, seeds

Red meat All kinds of red meats, heart, liver, kidney, tripe and rennet, tongue, brain, head sheep \& by meat, leg sheep meat

products

Poultry Chicken

Fish Fish

Fast foods Hamburger, pizza, sausage

Dairies Low-fat milk, yogurt, cheese, dough, High fat milk, chocolate milk, whole yogurt, High fat yogurt, cream cheese, cream, ice cream, curd

Solid oil Butter, margarine, hydrogenated fats, animal fats

Liquid oil A variety of cooking oils, mayonnaise, olive oil

Olive $\quad$ All kinds of pickle and salinity, red sauce, green olives

Yellow Squash, carrots

vegetables

Circus all kinds of raw cabbages

vegetables

Green Lettuce, spinach, vegetables, stewed vegetables, beans, bell peppers, green peas, green vegetables beans, celery, green pepper

Other Cucumbers, squash stew, eggplant, garlic, onions, turnips, mushrooms, tomatoes vegetables

Fruits Cantaloupe melon, Honeydew melon, Water melon, pears, apricot, apple, peach, nectarine, greengage, fig (fresh and dried), grapes, kiwi, grapefruit, orange, persimmon, tangerine, date,

Plum (red and yellow), mulberry, banana, Lemon(sweet and sour), sweet cherries, sour cherries, pomegranate, straw berry, juice, dried fruit 


\begin{tabular}{|ll|}
\hline $\begin{array}{l}\text { Food } \\
\text { group }\end{array}$ & Food items \\
\hline Dessert & $\begin{array}{l}\text { Biscuit, cracker, cake, all kinds of dried sweets, all kinds of cream sweets, halva, hard } \\
\text { candy, } \\
\text { all kinds of chocolate, gaz, sohan, honey, sugar, jam }\end{array}$ \\
\hline Snack & Fried potato, corn snack, potato chips \\
\hline Spices & All kind of spice \\
\hline $\begin{array}{l}\text { Caffeine } \\
\text { drinks }\end{array}$ & Tea and coffee \\
\hline $\begin{array}{l}\text { Industrial } \\
\text { drinks }\end{array}$ & Soft drinks, Canned fruits, canned juice \\
\hline
\end{tabular}

\section{Results}

Overall, dietary intakes of 257 participants were available for final analyses. General characteristics and sleep scores of participants has been summarized in Table 2. Mean age and BMI of participants were 37 \pm 2.88 years and $26.30 \pm 2.81 \mathrm{~kg} / \mathrm{m}^{2}$, respectively. Dietary intakes of study participants are shown in Table 3. We found three major dietary patterns that named those as Classic Iranian ( $\mathrm{Cl}$ ), Modern Iranian (MI), and High Protein Low Fruit and vegetables (HPLF). Main dietary components of these three patterns are shown in Table 4. The $\mathrm{Cl}$ pattern was mainly consisted of high-protein animal foods, fruit and vegetables, while, subjects in the MI pattern consumed high amounts of refined grains, solid oils, and caffeine drinks. Moreover, HPLF dietary pattern was consisted of high amounts of animal proteins and solid oils as well as low amounts of fruit and vegetables.

Table 2

General characteristics of included participants

\begin{tabular}{|ll|}
\hline Age $(\mathrm{y})$ & $\mathbf{3 7 \pm 2 . 8 8}$ \\
\hline $\mathrm{BMI}\left(\mathrm{kg} / \mathrm{m}^{2}\right)$ & $26.30 \pm 2.81$ \\
\hline Sleep score & $6.50 \pm 3.07$ \\
\hline Energy intake (Kcal/day) & $3701.38 \pm 2040.39$ \\
\hline Physical activity (Mets/week) & $2811.58 \pm 4114.16$ \\
\hline Married (\%) & 100 \\
\hline Educated (\%) & 60.5 \\
\hline Central obesity (\%) & 19.8 \\
\hline Supplements user (\%) & 2.3 \\
\hline
\end{tabular}


Table 3

Dietary intakes of study participants

\begin{tabular}{|lll|}
\hline Food group & Mean & SD \\
\hline Whole grains & 12.85 & 24.64 \\
\hline Refined grains & 957.66 & 1436.05 \\
\hline Egg & 25.62 & 22.40 \\
\hline Legumes \& nuts & 108.17 & 100.25 \\
\hline Red meat \& by products & 30.41 & 32.48 \\
\hline Poultry & 39.09 & 42.76 \\
\hline Fish & 15.55 & 26.38 \\
\hline Fast foods & 7.58 & 22.72 \\
\hline Dairies & 541.74 & 468.40 \\
\hline Solid oil & 18.52 & 18.84 \\
\hline Liquid oil & 10.87 & 10.72 \\
\hline Olive & 1.04 & 1.80 \\
\hline Yellow vegetables & 22.89 & 22.06 \\
\hline Circus vegetables & 9.05 & 14.23 \\
\hline Green vegetables & 108.07 & 90.44 \\
\hline Other vegetables & 216.29 & 209.91 \\
\hline Fruits & 629.33 & 929.71 \\
\hline Dessert & 48.91 & 58.08 \\
\hline Snack & 8.68 & 16.07 \\
\hline Spices & 3.64 & 3.39 \\
\hline Caffeine drinks & 953.48 & 1294.87 \\
\hline Industrial drinks & 83.28 & 146.61 \\
\hline
\end{tabular}


Table 4

Factor loadings of food groups in major dietary patterns

\begin{tabular}{|c|c|c|c|}
\hline \multirow[t]{2}{*}{ Food group } & \multicolumn{3}{|c|}{ Major dietary patterns } \\
\hline & Classic Iranian & High protein low fruit and vegetables & Modern Iranian \\
\hline Whole grains & .34 & .67 & -.35 \\
\hline Refined grains & .41 & .33 & .71 \\
\hline Egg & .61 & -.43 & .08 \\
\hline Legumes \& nuts & .62 & .19 & -.22 \\
\hline Red meat \& by products & .57 & .16 & -.05 \\
\hline Poultry & .19 & .46 & -.32 \\
\hline Fish & .48 & .50 & -.16 \\
\hline Fast foods & .78 & -.35 & -.04 \\
\hline Dairies & .67 & -.14 & .34 \\
\hline Solid oil & .44 & .33 & .40 \\
\hline Liquid oil & .57 & -.24 & .13 \\
\hline Olive & .32 & -.34 & .05 \\
\hline Yellow vegetables & .59 & -.10 & -.38 \\
\hline Circus vegetables & .72 & -.34 & -.17 \\
\hline Green vegetables & .79 & .20 & -.39 \\
\hline Other vegetables & .84 & -.42 & -.02 \\
\hline Fruits & .68 & .02 & -.24 \\
\hline Dessert & .18 & .34 & .08 \\
\hline Snack & .20 & .14 & -.16 \\
\hline Spices & .45 & -.01 & .46 \\
\hline Caffeine drinks & .29 & .26 & .82 \\
\hline Industrial drinks & .29 & .55 & .06 \\
\hline
\end{tabular}

Multivariate-adjusted odds ratios and $95 \% \mathrm{Cls}$ for sleep disturbance in relation to three major dietary patterns has been shown in Table 5. Before adjusting for the confounders, no significant association was found between adherence to the $\mathrm{Cl}$ pattern and risk of SDs [Odds Ratio (OR): 1.53; 95\% Confidence Interval (CI): $0.54,4.35]$. This finding remained unchanged after controlling for age and BMI in model 1 
(OR: $1.60 ; 95 \% \mathrm{Cl}: 0.54,4.76)$. It also did not change after additional controlling for marital status, education, and physical activity in model 2 (OR: 1.78; $95 \% \mathrm{Cl}: 0.57,5.60)$, and further adjustment for energy intake in model 3 (OR: 2.33; $95 \% \mathrm{Cl}$ : $0.69,7.81)$. There was also no significant association between adherence to the MI pattern and risk of SDs in the crude model (OR: $0.57 ; 95 \% \mathrm{Cl}: 0.20,1.62)$, and in the full-adjusted model (OR: $0.62 ; 95 \% \mathrm{Cl}: 0.20,1.93)$. Although no significant association was found between adherence to the HPLF dietary pattern and odds of SDs before adjustment (OR: 1.75; 95\% Cl: $0.62,4.99)$ and in the model 1 (OR: 1.84; 95\% Cl: 0.63, 5.36) and model 2 (OR: 1.82; 95\% Cl: 0.61, 5.46), our analyses showed a significant direct association through the full-adjusted model (OR: $3.92 ; 95 \% \mathrm{Cl}$ : $1.03,14.86)$. 
Table 5

Multivariate-adjusted odds ratios and $95 \%$ Cls for sleep disturbance in relation to major dietary patterns

\section{Tertiles of Classic Iranian pattern}

$\begin{array}{llll}T_{1}(n=85) & T_{2}(n=87) & T_{3}(n=85) & P^{a}\end{array}$

\begin{tabular}{lllll} 
Crude & 1 & $3.27(1.13,9.51)$ & $1.53(0.54,4.35)$ & 0.83 \\
\hline Model 1 & 1 & $3.31(1.12,9.81)$ & $1.60(0.54,4.76)$ & 0.41 \\
\hline Model 2 & 1 & $3.11(1.02,9.54)$ & $1.78(0.57,5.60)$ & 0.33 \\
\hline Model 3 & 1 & $3.11(1.00,9.68)$ & $2.33(0.69,7.81)$ & 0.15
\end{tabular}

Tertiles of High protein low fruit and vegetables pattern

\begin{tabular}{|c|c|c|c|c|}
\hline & $T_{1}(n=85)$ & $T_{2}(n=87)$ & $T_{3}(n=85)$ & $\mathrm{P}^{\mathrm{a}}$ \\
\hline Crude & 1 & $2.83(0.98,8.12)$ & $1.75(0.62,4.99)$ & 0.30 \\
\hline Model 1 & 1 & $2.96(1.01,8.65)$ & $1.84(0.63,5.36)$ & 0.27 \\
\hline Model 2 & 1 & $2.65(0.89,7.92)$ & $1.82(0.61,5.46)$ & 0.30 \\
\hline \multirow[t]{3}{*}{ Model 3} & 1 & $3.08(1.01,9.40)$ & $3.92(1.03,14.86)$ & 0.03 \\
\hline & \multicolumn{4}{|c|}{ Tertiles of Modern Iranian pattern } \\
\hline & $T_{1}(n=85)$ & $T_{2}(n=87)$ & $T_{3}(n=85)$ & $\mathrm{P}^{a}$ \\
\hline Crude & 1 & $1.06(0.38,2.97)$ & $0.57(0.20,1.62)$ & 0.30 \\
\hline Model 1 & 1 & $1.12(0.39,3.20)$ & $0.54(0.19,1.54)$ & 0.25 \\
\hline Model 2 & 1 & $0.91(0.30,2.75)$ & $0.50(0.17,1.50)$ & 0.22 \\
\hline Model 3 & 1 & $0.97(0.32,2.93)$ & $0.62(0.20,1.93)$ & 0.42 \\
\hline
\end{tabular}

Model 1: adjusted for age and BMI

Model 2: additionally, adjusted for marital status, education, and physical activity

Model 3: additional adjustment for energy intake

a The $\mathrm{P}$ for trend across increasing quintiles of adherence to dietary patterns was calculated using multivariable logistic regression by considering the categories as ordinal variables

\section{Discussion}

A significant association was found between adherence to the HPLF dietary pattern and the risk of SDs among shift workers of the cement factory. However, we failed to find such associations for $\mathrm{Cl}$ or $\mathrm{MI}$ dietary patterns. 
This study is the first investigation about the "Relations of Dietary patterns and sleep disorders in shift workers" association of dietary patterns with risk of sleep disorders among shift workers in Iran. In a recent cross-sectional study among female university students, four major dietary patterns including mixed, high protein, western, and healthy were identified. Significant association was found only for the mixed dietary pattern in relation to the increased sleep quality (21). It seems that subjects on the mixed dietary pattern received sufficient amounts of different micro- and macronutrients. Another study among schoolchildren found a significant inverse association between "dairy, bread, green leaves, maize/potatoes and sausages" dietary pattern and sleep duration (22). Low intake of fruit and vegetables and high levels of refined carbohydrates were common among participants in that pattern. Other studies also have shown that a higher diet quality is linked to a reduced risk of sleep disorders (23, 24). Overall, it seems that consumption of high-quality diets, rich in fruits and vegetables, is linked to a reduced risk of SDs, while, adherence to a dietary patterns with high amounts of saturated fatty acids and animal food items and low amounts of fruit and vegetables is linked to an elevated risk of SDs (25-27).

The exact mechanisms through which dietary intakes is associated with sleep quality are unknown. Consumption of a high-carbohydrate and low-protein diet has been associated to the best quality of sleep. Tryptophan, a precursor of serotonin (28), enters the brain in a competitive manner with large-chain neutral amino acids (LCNAAs) (29). Dietary carbohydrates, unlike proteins, increase brain tryptophan concentrations in the circulation (30). Tryptophan enters the brain and up-regulates serotonin production (31), which then promotes sleeping (32). In contrast, diets high in solid oils and saturated fatty acids and low in fibers may produce more nighttime arousals, and reduce overall sleep quality (21). Diets high in fats commonly have low amounts of carbohydrates. In addition, fat intake stimulates postprandial release of cholecystokinin, a satiety hormone released by the duodenum (33). Injection of cholecystokinin into rats has resulted in sleep promotion (34). Moreover, cholecystokinin was reported to be positively correlated with fatigue (35). Furthermore, meal time is another important factor that influences on the association of dietary intakes with sleep quality (21). Nocturnal eating, in particular consumption of a high-fat diet, is associated to the reduced overall quality of sleep (36). Therefore, night shift workers are susceptible to sleep disorders caused by nocturnal eating which becomes more serious by consumption of a high-fat and low fruit and vegetables diet.

This is the first study on the association of dietary patterns with sleep quality among shift workers. Adjustment for a list of probable confounding factors is a strength of the current study. However, limitations of the study also should be taken into account. This study had a cross-sectional design, therefore, it is impossible to confer the causality. In addition, a limited number of study participants had dietary data. A validated FFQ was used to assess dietary intakes of participants, however, misclassification of participants by using this assessment should not be neglected. Finally, sleep quality was measured by using a questionnaire in our study. Hence, self-reported information might be over- or under-estimated depending on the subject's memory.

In conclusion, current study showed a significant direct association between a dietary pattern high in animal proteins and solid oils and low in fruit and vegetables with risk of sleep disorders among shift 
workers in a cement factory. However, we failed to find such an association for two other dietary patterns. Further studies with large sample sizes are required to shed light in this issue.

\section{Declarations}

Ethics approval and consent to participate: This research has been approved by the Research Ethics Committee of Tehran University of Medical Sciences and Health Services, Tehran, Iran. Full explanations about the purposes and methods of the study were given to the participants and then their written consent was obtained.

Consent for publication: The authors would like to advise that all authors listed have contributed to the work and approved the content of the submitted manuscript. All authors have agreed to submit the manuscript to the "annals of general psychiatry".

Availability of data and material: All data generated or analysed during this study are included in this published article [Relations of Dietary patterns and sleep disorders in shift workers].

Competing interests: There is no conflict of interest in this study to declare.

Funding: This research has been supported by the Research Ethics Committee of Tehran University of Medical Sciences and Health Services, Tehran, Iran.Grant no. 30331-161-03-94.

Authors' contributions: Gity Sotoudeh conceived and developed the idea for the paper and revised the manuscript; Reihaneh Khorasaniha contributed to data collection and wrote numerous drafts; Alireza Milajerdi and Farahnaz Khajehnasiri contributed to data analysis and interpretation of the data.

Acknowledgements: The authors would like to appreciate the Tehran cement factory workers for their participation, cooperation, and collaboration in this study.

\section{References}

1. Garbarino S, De Carli F, Nobili L, Mascialino B, Squarcia S, Penco MA, et al. Sleepiness and sleep disorders in shift workers: a study on a group of Italian police officers. Sleep. 2002;25(6):642-7.

2. Burke R, Charles LE, Burchfiel CM, Fekedulegn D, Vila B, Hartley TA, et al. Shift work and sleep: the Buffalo Police health study. Policing: An International Journal of Police Strategies \& Management. 2007.

3. Barandas R, Landgraf D, McCarthy MJ, Welsh DK. Circadian clocks as modulators of metabolic comorbidity in psychiatric disorders. Current psychiatry reports. 2015;17(12):98.

4. Fischer FM. What do petrochemical workers, healthcare workers, and truck drivers have in common? Evaluation of sleep and alertness in Brazilian shiftworkers. Cadernos de Saúde Pública. 2004;20(6):1732-8. 
5. Nena E, Katsaouni M, Steiropoulos P, Theodorou E, Constantinidis TC, Tripsianis G. Effect of shift work on sleep, health, and quality of life of health-care workers. Indian journal of occupational and environmental medicine. 2018;22(1):29.

6. Dashti HS, Scheer FA, Jacques PF, Lamon-Fava S, Ordovás JM. Short sleep duration and dietary intake: epidemiologic evidence, mechanisms, and health implications. Advances in nutrition. 2015;6(6):648-59.

7. Zhao M, Tuo H, Wang S, Zhao L. The Effects of Dietary Nutrition on Sleep and Sleep Disorders. Mediators of Inflammation. 2020;2020.

8. Svendsen M, Blomhoff R, Holme I, Tonstad S. The effect of an increased intake of vegetables and fruit on weight loss, blood pressure and antioxidant defense in subjects with sleep related breathing disorders. European journal of clinical nutrition. 2007;61(11):1301-11.

9. Noorwali E, Hardie L, Cade J. Bridging the reciprocal gap between sleep and fruit and vegetable consumption: A review of the evidence, potential mechanisms, implications, and directions for future work. Nutrients. 2019;11(6):1382.

10. Moreira P, Santos S, Padrão P, Cordeiro T, Bessa M, Valente H, et al. Food patterns according to sociodemographics, physical activity, sleeping and obesity in Portuguese children. International journal of environmental research and public health. 2010;7(3):1121-38.

11. Wyatt JK, Cajochen C, Cecco AR-D, Czeisler CA, Dijk D-J. Low-dose repeated caffeine administration for circadian-phase-dependent performance degradation during extended wakefulness. Sleep. 2004;27(3):374-81.

12. Orbeta RL, Overpeck MD, Ramcharran D, Kogan MD, Ledsky R. High caffeine intake in adolescents: associations with difficulty sleeping and feeling tired in the morning. Journal of Adolescent Health. 2006;38(4):451-3.

13. Zhao I, Turner C. The impact of shift work on people's daily health habits and adverse health outcomes. Australian Journal of Advanced Nursing, The. 2008;25(3):8.

14. Kurotani K, Kochi T, Nanri A, Eguchi M, Kuwahara K, Tsuruoka H, et al. Dietary patterns and sleep symptoms in Japanese workers: the Furukawa Nutrition and Health Study. Sleep medicine. 2015;16(2):298-304.

15. Katagiri R, Asakura K, Kobayashi S, Suga H, Sasaki S. Low intake of vegetables, high intake of confectionary, and unhealthy eating habits are associated with poor sleep quality among middleaged female Japanese workers. Journal of occupational health. 2014:14-0051-OA.

16. Esfahani FH, Asghari G, Mirmiran P, Azizi F. Reproducibility and relative validity of food group intake in a food frequency questionnaire developed for the Tehran Lipid and Glucose Study. Journal of epidemiology. 2010;20(2):150-8.

17. Johns MW. A new method for measuring daytime sleepiness: the Epworth sleepiness scale. sleep. 1991;14(6):540-5.

18. Johns MW. Sensitivity and specificity of the multiple sleep latency test (MSLT), the maintenance of wakefulness test and the epworth sleepiness scale: failure of the MSLT as a gold standard. Journal 
of sleep research. 2000;9(1):5-11.

19. Craig CL, Marshall AL, Sjöström M, Bauman AE, Booth ML, Ainsworth BE, et al. International physical activity questionnaire: 12-country reliability and validity. Medicine \& science in sports \& exercise. 2003;35(8):1381-95.

20. Moghaddam MB, Aghdam FB, Jafarabadi MA, Allahverdipour H, Nikookheslat SD, Safarpour S. The Iranian Version of International Physical Activity Questionnaire (IPAQ) in Iran: content and construct validity, factor structure, internal consistency and stability. World applied sciences journal. 2012;18(8):1073-80.

21. Bazyar H, Javid AZ, Dasi E, Sadeghian M. Major dietary patterns in relation to obesity and quality of sleep among female university students. Clinical Nutrition ESPEN. 2020.

22. de Oliveira MT, Lobo AS, Kupek E, de Assis MAA, Cezimbra VG, Pereira LJ, et al. Association between sleep period time and dietary patterns in Brazilian schoolchildren aged 7 to 13 years. Sleep Medicine. 2020.

23. Khani-Juyabad S, Setayesh L, Tangestani H, Ghodoosi N, Sajjadi SF, Badrooj N, et al. Adherence to Lifelines Diet Score (LLDS) is associated with better sleep quality in overweight and obese women. Eating and Weight Disorders-Studies on Anorexia, Bulimia and Obesity. 2020:1-8.

24. Reid M, Maras JE, Shea S, Wood AC, Castro-Diehl C, Johnson DA, et al. Association between diet quality and sleep apnea in the Multi-Ethnic Study of Atherosclerosis. Sleep. 2019;42(1):zsy194.

25. Chaput J-P. Sleep patterns, diet quality and energy balance. Physiology \& behavior. 2014;134:86-91.

26. Daneshzad E, Keshavarz S-A, Qorbani M, Larijani B, Bellissimo N, Azadbakht L. Association of dietary acid load and plant-based diet index with sleep, stress, anxiety and depression in diabetic women. British Journal of Nutrition. 2020;123(8):901-12.

27. Jansen EC, Stern D, Monge A, O’Brien LM, Lajous M, Peterson KE, et al. Healthier dietary patterns are associated with better sleep quality among mid-life Mexican women. Journal of Clinical Sleep Medicine. 2020:jcsm. 8506.

28. Afaghi A, O'Connor H, Chow CM. High-glycemic-index carbohydrate meals shorten sleep onset. The American journal of clinical nutrition. 2007;85(2):426-30.

29. Gruenbaum SE, Chen EC, Sandhu MRS, Deshpande K, Dhaher R, Hersey D, et al. Branched-Chain Amino Acids and Seizures: A Systematic Review of the Literature. CNS drugs. 2019:1-16.

30. Wurtman RJ, Wurtman JJ, Regan MM, McDermott JM, Tsay RH, Breu JJ. Effects of normal meals rich in carbohydrates or proteins on plasma tryptophan and tyrosine ratios. The American journal of clinical nutrition. 2003;77(1):128-32.

31. Afaghi A, O'Connor $\mathrm{H}$, Chow CM. Acute effects of the very low carbohydrate diet on sleep indices. Nutritional Neuroscience. 2008;11(4):146-54.

32. Kapás L, Obál Jr F, Alföldi P, Rubicsek G, Penke B, Obál F. Effects of nocturnal intraperitoneal administration of cholecystokinin in rats: simultaneous increase in sleep, increase in EEG slow-wave activity, reduction of motor activity, suppression of eating, and decrease in brain temperature. Brain research. 1988;438(1-2):155-64. 
33. Shaibani A, Frisaldi E, Benedetti F. Placebo response in pain, fatigue, and performance: possible implications for neuromuscular disorders. Muscle \& nerve. 2017;56(3):358-67.

34. Crispim CA, Zimberg IZ, dos Reis BG, Diniz RM, Tufik S, de Mello MT. Relationship between food intake and sleep pattern in healthy individuals. Journal of Clinical Sleep Medicine. 2011;7(6):659-64. 